\title{
Reinventing the atrial fibrillation wheel
}

Isidore Dinga Madou, MD, Tsuyoshi Kaneko, MD, and Sary F. Aranki, MD

From the Division of Cardiac Surgery, Department of Surgery, Brigham and Women's Hospital, Harvard School of Medicine, Boston, Mass.

Disclosures: Authors have nothing to disclose with regard to commercial support.

Received for publication June 7, 2018; revisions received June 7, 2018; accepted for publication June 8, 2018.

Address for reprints: Sary F. Aranki, MD, Division of Cardiac Surgery, Department of Surgery, Brigham and

Women's Hospital, 75 Francis St, Boston, MA 02115 (E-mail: saranki@partners.org).

J Thorac Cardiovasc Surg 2018;156:1526

0022-5223/\$36.00

Copyright $(2018$ by The American Association for Thoracic Surgery

https://doi.org/10.1016/j.jtcvs.2018.06.033

In this issue of the Journal, Mehta and colleagues ${ }^{1}$ report their 10-year experience with "De Novo Atrial Fibrillation After Mitral Valve Surgery," defined as new-onset atrial fibrillation (AF) occurring more than 90 days after discharge. The cause was heterogeneous, with half of the patients having degenerative pathology. The incidence of de novo AF was $14 \%$ and $23 \%$ at 5 and 10 years, respectively. Multivariable risk factors were tricuspid valve surgery, aortic valve surgery, and older age. Obviously, significantly more patients with AF were anticoagulated, with a strong but not significant trend toward an increased risk of stroke. Amazingly, there was no difference in survival as would be expected. The aim of this study, as stated by the authors, was to propose conducting a future prospective randomized study to determine if a prophylactic ablation procedure at the time of mitral valve surgery may result in reduction of de novo AF. They even calculated a sample size that will show a $40 \%$ reduction at 5 years.

This is a well-designed and well-written study that addresses the important issue of AF after mitral valve surgery, which is a surrogate for increased risk of associated embolic and anticoagulation-related adverse sequelae. It helps us identify the predictors that could be targeted to reduce $\mathrm{AF}$ incidence. However, it must be pointed out that $28 \%$ of the patients had no rhythm information and had to be excluded. Rhythm monitoring was not homogenous, and this raises the question of the true incidence AF. One interesting finding that the authors did not discuss is found in Table 1 and concerns the CHA2DS2-VASc score, the updated version of CHADS2 score that estimates the risk of stroke in patients with nonrheumatic atrial fibrillation. Patients with higher scores had a significantly higher incidence of AF. Although this score is used to calculate the risk of embolic events and the need

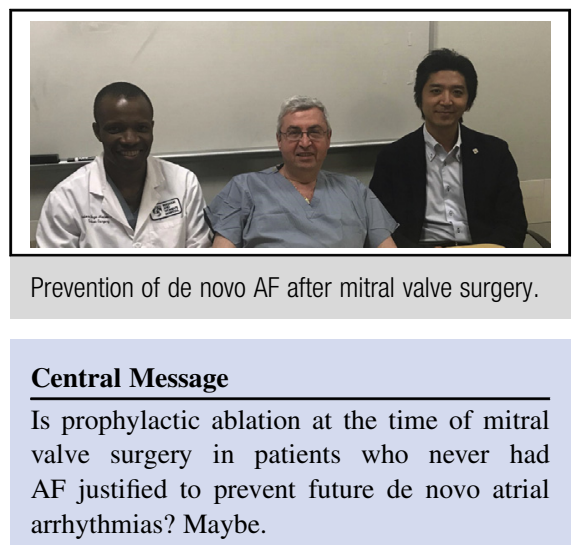

See Article page 1515 .

for anticoagulation therapy, it also may have a role in prediction of AF.

The Framingham study ${ }^{2}$ showed that there is an absolute 1 in 4 lifetime risk for the development of AF, especially in elderly patients, those with prior myocardial infarction, and those with congestive heart failure. In patients without myocardial infarction or congestive heart failure, the lifetime risk is 1 in 6 . It seems that the results of the current study closely mimic those numbers. Reinventing the AF wheel may or may not be on the horizon. Perhaps the current study is a small step in that endeavor. In the meantime, we are not sure that a prophylactic ablation procedure with left atrial appendage resection can be justified.

Finally, the results of the randomized Catheter Ablation Versus Anti-Arrhythmic Drug Therapy for Atrial Fibrillation trial (presented at the Heart Rhythm Society 2018 annual meeting) showed that ablation was not superior to drug therapy for cardiovascular outcomes at 5 years. This may cast ablation in a negative light and cause public scrutiny of these procedures in the future.

\section{References}

1. Mehta KC, McCarthy PM, Andrei A-C, Kruse J, Shi H, Chuyla A, et al. De novo atrial fibrillation after mitral valve surgery. J Thorac Cardiovasc Surg. 2018;156: 1515-25.e11.

2. Lloyd-Jones DM, Wang TJ, Leip EP, Larson MG, Levy D, Vassan RS, et al. Lifetime risk for development of atrial fibrillation: The Framingham Heart Study Circulation. 2004;110:1042-6. 